\title{
Development of a Highway Performance Index for Upgrading Decision Making - Case Study for a Provincial Road Network in a Developing Country
}

\author{
H. R. Pasindu, Lalith Sirisumana, and D. N. D. Jayaratne
}

\begin{abstract}
Provincial level and Local roads comprise nearly $50 \%$ of the road network in mileage in Sri Lanka. They play a pivotal role in providing access to the local communities especially in rural areas and an essential component of the economic development of those areas. These roads are under the purview of Local Councils and Provincial Road Development Authorities. Most of these roads do not conform to the design guidelines as they were often developed from local foot paths or gravel roads. Therefore, the travel speeds are very low and safety issues have arisen with the increase in travel demand and the use of motorized vehicles. Therefore, there is need to upgrade these roads to the appropriate design standards to ensure safe and efficient mobility to the road users. However, the road agencies have limited funding to implement upgrading projects on the entire network. Thus, it is pertinent that there is a methodology to prioritize the roads based on the current operational performance so that the funding allocation can be done in the most effective manner. Road upgrading in the context of the study is focused on roadway improvements such as alignment, road width, shoulder etc. In addition to the limited funding, the agencies also lack the technical capacity to carryout detailed investigation and surveys on highway performance that are typically carried out in other road agencies at national level. Therefore, the study proposes a simplified methodology to evaluate the performance index of the road based on its roadway and operational characteristics, to be used to assess road network condition and identify upgrading needs for a highway agency of a low volume road network.
\end{abstract}

Index Terms - Highway performance index, provincial roads, developing country, level of service.

\section{INTRODUCTION}

$\mathbf{L}$ ow volume roads in Sri Lanka are generally under the $\Lambda_{\text {purview of the Local Government or the Provincial }}$ Councils. These are categorized as ' $\mathrm{C}$ ' Class and ' $\mathrm{D}$ ' Class roads which form more that $50 \%$ of the road network in the country in terms of road-kilometers [1]. The government has invested heavily on improving the road condition of these roads and has upgraded them to asphalt concreting or concrete

H.R. Pasindu is with the Department of Civil Engineering, University of Moratuwa, Katubedda, Sri Lanka (e-mail: 168078m@uom.lk)

L. Sirisumana is with the Western Provincial Road Development Authority, Sri Lanka

D.N.D. Jayaratne is with the ${ }^{3}$ Department of Civil Engineering, University of Moratuwa, Katubedda, Sri Lanka. pavement roads in the recent years [2] under World Bank, Asian Development Bank and other monetary institution loans. However, due to various reasons there has not been major improvements made to the roadway characteristics such as lane width, shoulder, radius of curvature of these roads. The improvements in road surface condition, population growth and increased use in motorization has resulted in the increase in travel demand on these roads. Thus, creating a need to upgrade these roads to conform with proper design requirements to ensure safe and efficient mobility to the road users.

In addition to the limited funding, the agencies also lack the technical capacity to carryout detailed investigations and surveys on highway performance that are typically carried out in other road agencies at national level. Therefore, any methodology used to evaluate the performance of provincial road networks should be based on data that can be easily collected during the routine network survey. This ensures the continuity in the application of the method in the decisionmaking process.

The study proposes a simplified methodology to calculate performance index of roads to be used for highway upgrading prioritization. Road upgrading in the context of the study is focused on roadway improvements such as alignment, road width, shoulder etc. not necessarily surface or pavement type improvements. Therefore, the study focuses on the roadway and operating characteristics rather than the pavement condition as the intention is to evaluate their performance with respect to planning level decision making where roads will be selected for upgrading. It is deemed that the maintenance management system would incorporate the pavement condition of the roads.

\section{Evaluation of Highway Functional Performance}

Highway performance relates to the structural and functional performance of the road. Functional performance is represented by the mobility, rider comfort and safety. These are predominately affected by the roadway characteristics such as alignment, gradient, curvature, road width, shoulder condition, surface condition; and operating characteristics such as traffic volume, heavy vehicle composition, presence of non- motorized traffic etc. Most studies represent highway functional performance via level of service which mainly addresses the mobility aspect of the road. 
A. Level Of Service analysis (LOS) for two lane highways

Level of service (LOS) is a qualitative measure used to relate the quality of traffic service. LOS is used to analyze highways and other transport facilities by categorizing traffic flow and assigning quality levels of traffic based on performance measures like speed, density, etc. LOS is generally represented by the letters A through F; where LOS A represents the best condition and LOS F represents the worst.

The US Highway Capacity Manual (HCM) 2010 defines LOS for two lane roads using three performance measures; namely, Average Travel Speed (ATS), Percent Time Spent Following (PTSF), and Percent of Free Flow Speed (PFFS) [3]. ATS reflects the mobility on the highway. PTSF which is the average percentage of time that vehicles must travel in platoons behind slower vehicles due to its inability to pass represents the freedom to maneuver and the comfort and convenience of travel. PFFS represents the ability of vehicles to travel at or near the posted speed limit. The HCM has defined three classes of two lane highways, and above mentioned performance measures are used accordingly. The HCM 2010 LOS depends on the highway class, lane width, shoulder width, access point density, and terrain type, percentage of no passing zones, design speed, traffic volume, directional split and heavy vehicle percentage.

The Indonesian HCM (IHCM) 1993 does not define LOS as in the US HCM [4]. Instead it encourages the user to evaluate the traffic condition using a factor defined as the 'degree of saturation' which is the ratio between demand flow and the capacity of a given segment. The capacity of an urban two-lane road depends on carriageway width, curb/shoulder width, directional split, side friction, city size and traffic composition.

The Indian Road Congress, IRC: 64-1990 provides some guidelines for capacity of two-lane roads [5]. It defines LOS similar to the US HCM but information regarding LOS evaluation is sparse. The Capacity/LOS varies with carriageway width, shoulder type, terrain, curvature and traffic composition.

Considering the above manuals, the roadway characteristics found to be common are carriageway width, shoulder width, and the road alignment geometry. In terms of operating characteristics, the traffic volume, composition, and directional split were incorporated in all models.

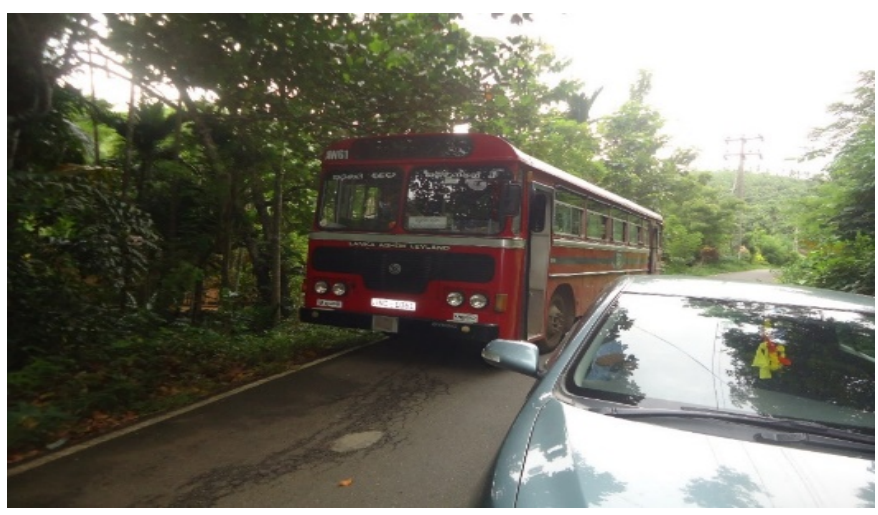

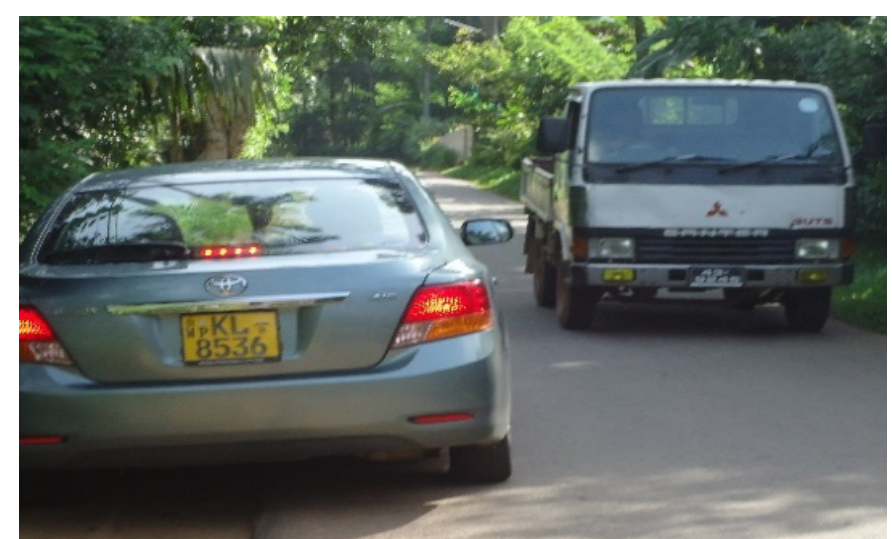

Fig. 1. Limited provision of passing bays and low carriageway width

B. Limitations in the level of service approach in evaluation of functional performance for low volume roads

The level of service analysis approach is often used in the planning level studies to evaluate the traffic related operating conditions of the road. Therefore, the methodologies developed to calculate the LOS account for the factors that affect the traffic flow [6-8]. They do not satisfactorily address the issues related to safety etc. since the underlying assumption in those methods is that the highways being evaluated is designed as per the design guidelines. This as illustrated earlier is not applicable to the provincial level roads.

\section{Methodology}

A. Identification of Main factors affecting Highway Functional Performance

A sample of 50 roads were selected for the study. General characteristics of the roads are given in Table I. All these roads are two lane roads with moderate traffic levels.

TABLE I

SUMMARY OF THE ROADWAY AND OPERATING CHARACTERISTICS OF THE SAMPLE ROADS

\begin{tabular}{cccc}
\multicolumn{4}{c}{ SAMPLE ROADS } \\
\hline Characteristic & Average & Minimum & Maximum \\
\hline Vehicle Speed $(\mathrm{km} / \mathrm{h})$ & 17.2 & 4.8 & 38.4 \\
Carriageway width $(\mathrm{m})$ & 4.1 & 3.0 & 8.0 \\
Road length $(\mathrm{km})$ & 3.6 & 0.45 & 11.3 \\
Heavy vehicle $\%$ & $10 \%$ & $0.2 \%$ & $30 \%$ \\
\hline
\end{tabular}

Field surveys were carried out on the sample road sections to identify the main issues prevalent on the roads and record the roadway and operational characteristics such as width, shoulder, average travel speed, road furniture etc. The common issues noted during the surveys are as follows (see Figs. 1 and 2),

- Vertical alignment, horizontal alignment, and curvature transition does not conform to design requirements

- Variability in road width

- Lack of shoulder or shoulder in poor conditions

- There is no specified right of way

- Inadequate provision of structures 
- Lack of or deteriorated pavement markings, road signs and road furniture

- Lack of passing bays and bus bays where public transport services are in operation

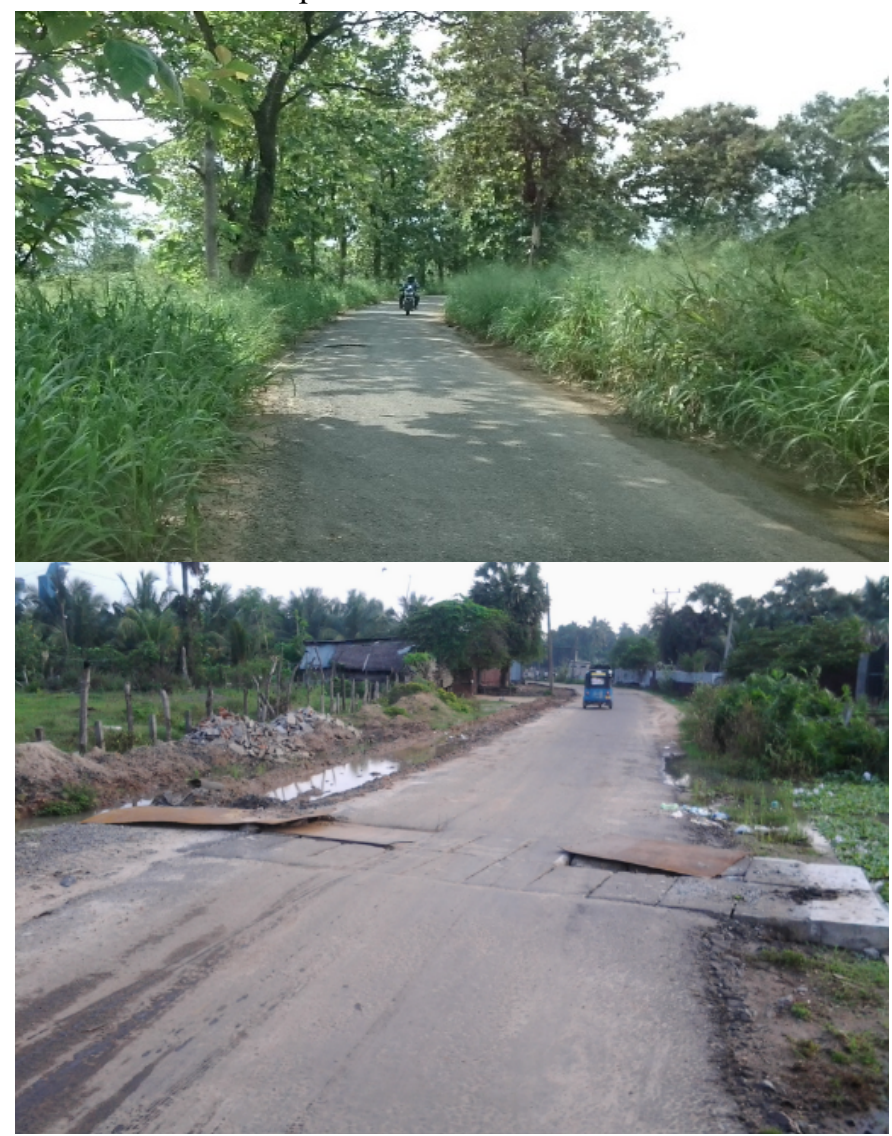

Fig. 2. Limited shoulder width and lack of proper highway structures

\section{B. Selection of key factors affecting highway performance}

Based on the issues observed, key factors identified were given to the senior engineers in the respective highway agency to rank and assign a weightage out of 100 . The weightage and ranking was to be decided to represent their relative importance with respect to making a decision regarding upgrading the particular road. The factors were ranked based on the average weightage received from the expert engineers and is given in Table II.

TABLE II

RANKING AND AVERAGE WEIGHT AGE OF THE IDENTIFIED FACTORS

\begin{tabular}{lcc}
\hline Factor & Average weightage & Rank \\
\hline Road width & 20.6 & 1 \\
Shoulder width & 19.0 & 2 \\
Right of Way & 14.4 & 3 \\
Passing Bays & 12.5 & 4 \\
Highway Structures & 10.3 & 5 \\
Narrow Bends & 9.6 & 6 \\
Road Furniture & 9.2 & 7 \\
Average Speed & 4.4 & 8 \\
\hline
\end{tabular}

The paved or unpaved shoulder area is on either side of the road. Right of way is the available area for future widening of the road etc. Passing bays refer to availability of passing bays on narrow roads, especially when there is a bus route etc.
Highway structures refer to the bridges, culverts etc. Narrow Bends are defined as those that require motorists to substantially slow down their travel speed in order to take the curve, these are often non-standard horizontal curves. Road furniture refer to the road signs, pavement markings, lighting etc. Average speed is the travel speed measured along the road section during low traffic flow conditions, uncongested flow.

The ranking and the relative weightages clearly depict the relevant issues at the provincial level road network. Low weightage is assigned to the factors such as vehicle speed, compared to road width. The shoulder width has also taken high importance due to its impact on pedestrians and nonmotorized traffic as well as the longevity of the pavement sections. The main function of these roads is accessibility hence, roadway parameters that affect accessibility such as road width, shoulder takes precedence over factors that affect mobility such as narrow bends. Another key factor is the highway structures such as bridges, culvert, road side slopes which are often neglected or under maintained in routine maintenance operations

\section{Assigning ratings for each factor based on their measured parameters}

The objective of the study is to calculate a performance index. Therefore, the observed parameters of each of the variables that can be either measurable or qualitative must be transferred into a numerical value for the purpose of analysis. The study looked at the variation of each parameter and assigned an appropriate rating normalized to give a value less than or equal to 1 for pre-defined categories for each factor considering their relative impact on the performance of the road. For example, road width exceeding $6 \mathrm{~m}$ was deemed adequate for the level of mobility expected from the road, therefore a score of 1 was assigned. Relative to that, a road section with less than $3.5 \mathrm{~m}$ width was given 0.3 . The relative score or rating between the categories did not always vary uniformly. When considering the speed, a speed range of 30$50 \mathrm{~km} / \mathrm{h}$ was given score of 0.9 relative to the maximum score of 1 given for speeds exceeding $60 \mathrm{~km} / \mathrm{h}$. Again, consideration is given to the expected function of the road.

TABLE III

GiVES THE ASSIGNED RATINGS FOR EACH FACTOR AND THEIR SUB CATEGORIES

\begin{tabular}{lll}
\hline \multicolumn{1}{c}{ Criteria } & Observed parameter categories & $\begin{array}{c}\text { Assigned } \\
\text { rating }\end{array}$ \\
\hline \multirow{3}{*}{ Road width } & $3.5-4.5 \mathrm{~m}$ & 0.3 \\
& $4.5-6.0 \mathrm{~m}$ & 0.5 \\
& $>6 \mathrm{~m}$ & 0.8 \\
& $<0.6 \mathrm{~m}$ & 1 \\
Shoulder & $0.6-1.0 \mathrm{~m}$ & 0.3 \\
width & $1.0-1.5 \mathrm{~m}$ & 0.5 \\
& $>1.5 \mathrm{~m}$ & 0.8 \\
& $>6 \mathrm{Nos} . / \mathrm{km}$ & 1 \\
\multirow{2}{*}{ Narrow Bends } & $3-6$ Nos. $/ \mathrm{km}$ & 0.1 \\
& $<3$ Nos. $/ \mathrm{km}$ & 0.3 \\
\hline
\end{tabular}




\begin{tabular}{|c|c|c|}
\hline & None & 1 \\
\hline \multirow{4}{*}{ Right of Way } & $<3.0 \mathrm{~m}$ & 0.3 \\
\hline & $3.0-5.0 \mathrm{~m}$ & 0.5 \\
\hline & $5.0-7.0 \mathrm{~m}$ & 0.8 \\
\hline & $7 \mathrm{~m}$ & 1 \\
\hline \multirow{3}{*}{ Structures } & Require minor improvements & 1 \\
\hline & Major repair to culverts, bridges etc. & 0.6 \\
\hline & $\begin{array}{l}\text { Reconstruction / Widening of bridges, } \\
\text { reconstruction of culverts etc. required }\end{array}$ & 0.1 \\
\hline \multirow{3}{*}{ Passing Bays } & $<3$ Nos. $/ \mathrm{km}$ & 0.5 \\
\hline & 3-6 Nos./km & 0.7 \\
\hline & $>6$ Nos. $/ \mathrm{km}$ & 1 \\
\hline \multirow{4}{*}{$\begin{array}{l}\text { Road } \\
\text { Furniture }\end{array}$} & $\begin{array}{l}\text { All required road signs and } \\
\text { markings are available }\end{array}$ & 1 \\
\hline & $\begin{array}{l}\text { Minor improvements/repairs to } \\
\text { existing } \\
\text { and less than } 20 \% \text { are missing }\end{array}$ & 0.7 \\
\hline & $\begin{array}{l}\text { More than } 50 \% \text { are missing } \\
\text { and/or require major repair }\end{array}$ & 0.3 \\
\hline & $\begin{array}{l}\text { Less than } 10 \% \text { of the required road } \\
\text { signs } \\
\text { and markings are existing }\end{array}$ & 0 \\
\hline \multirow{5}{*}{ Vehicle Speed } & $<10 \mathrm{~km} / \mathrm{h}$ & 0.1 \\
\hline & $10-20 \mathrm{~km} / \mathrm{h}$ & 0.3 \\
\hline & $20-30 \mathrm{~km} / \mathrm{h}$ & 0.6 \\
\hline & $30-50 \mathrm{~km} / \mathrm{h}$ & 0.9 \\
\hline & $>50 \mathrm{~km} / \mathrm{h}$ & 1 \\
\hline
\end{tabular}

D. Calculation of performance index for the road

The weighted rating for each road section was calculated to represent its performance index $\left(P I_{i}\right)$ for road $i$ as,

where,

$$
P I_{i}=\sum_{k=1}^{n} w_{k} r_{k}
$$

$\mathrm{w}_{\mathrm{k}}$ - weightage for factor $\mathrm{k}$;

$\mathrm{r}_{\mathrm{k}}$ - rating for factor $\mathrm{k}$;

$\mathrm{n}$-total number of factors.

\begin{tabular}{lc}
\hline \multicolumn{1}{c}{$\boldsymbol{K}$} & $\boldsymbol{w}_{\boldsymbol{k}}$ \\
\hline Road width & 20.5 \\
Shoulder width & 19.0 \\
Right of Way & 14.4 \\
Passing Bays & 12.5 \\
Highway Structures & 10.3 \\
Narrow Bends & 9.6 \\
Road Furniture & 9.2 \\
Average Speed & 4.5 \\
\hline
\end{tabular}

The ratings for each factor will be assigned based on the data collected during the inventory surveys.

\section{CAse Study}

The derived formula is applied to evaluate the performance index for selected 60 road sections in the same network. The same road sections are given to the senior engineer in the respective road agency to assign a subjective performance rating (out of 100) giving consideration to the need for upgrading that road section based on their observation and experiences of the roads concerned. The scale of the rating defined as follows:

- 100: Requires no upgrading, roadway characteristics conform to design guidelines standards, operating speeds are satisfactory.

- 50: Sections of the roads need improvements, such as improvement in alignment at curves, introduction of a passing bay, improvement of shoulders etc.

- 0 : Upgrading of the road required, including road widening for significant proportion, improvements to the road alignment etc.

The ratings assigned by the engineers were compared with the calculated values from the performance index function given in Equation 1. The ratings for each factor was assigned based on the observed roadway characteristics.

The results are shown in Fig. 3, which indicates a satisfactory fit between the calculated values and engineers' ratings. The correlation coefficient was 0.929 and RMSE value was 5.72 . This shows the proposed model satisfactorily represents the engineers' evaluation

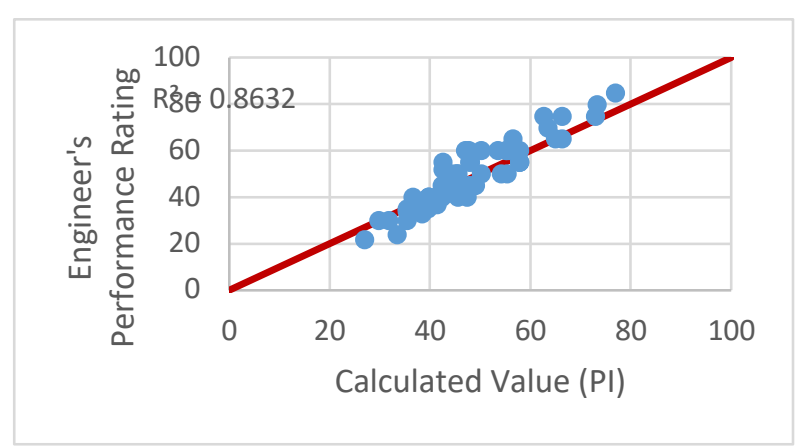

Fig. 3. Scatter plot of Engineer's performance rating and calculated performance index

\section{A. Model calibration method}

A regression analysis was carried out on the data set using a statistical software to identify the impact of each coefficient on the predicted output of the model at $95 \%$ confidence interval with the null hypothesis $\left(\mathrm{H}_{0}\right)$ defined such that a given coefficient is equal to zero.

\section{$\mathrm{H}_{0}$ : Given coefficient is equal to zero \\ $\mathrm{H}_{1}$ : Given coefficient is not equal to zero}

From the analysis the p-values for 'Right of way' and 'Passing bays' were observed to be greater than 0.05 . Hence the null hypothesis cannot be rejected. Therefore, the model was reconfigured by eliminating the two coefficients.

To improve the accuracy of the reconfigured model an optimization approach as follows was applied,

$\quad \operatorname{Min} \sum\left(\mathrm{y}_{\mathrm{i}}-P \mathrm{I}_{\mathrm{i}}\right)^{2}$
where, $\quad P I_{i}=\sum_{k=1}^{n} w_{k} r_{k}$

$\mathrm{y}_{\mathrm{i}}$ is the engineers subjective rating of the road section

$$
\text { such that, } \quad \begin{aligned}
\sum_{k=1}^{n} w_{k} & =100 \\
w_{k} & \geq 0
\end{aligned}
$$


The model coefficients of each factors were optimized to minimize the SSE value between the calculated value and the engineers rating, subject to the constraints that the summation of coefficients should be equal to 100 (to ensure compatibility with engineers rating scale) and non-negativity constraints. The model coefficients derived from the optimization approach is compared with the weightages assigned by the engineers in Table IV.

TABLE IV COMPARISON OF MODEL COEFFICIENTS

\begin{tabular}{lcc}
\hline \multicolumn{1}{c}{ Factor k } & $\begin{array}{c}\text { Assigned } \\
\text { weightages }\end{array}$ & $\begin{array}{c}\text { Results from the } \\
\text { Optimization analysis }\end{array}$ \\
\hline Road width & 20.5 & 28.7 \\
Shoulder width & 19.0 & 24.7 \\
Right of Way & 14.4 & NA \\
Passing Bays & 12.5 & NA \\
Highway Structures & 10.3 & 33.4 \\
Narrow Bends & 9.6 & 4.7 \\
Road Furniture & 9.2 & 3.3 \\
Average Speed & 4.5 & 5.2 \\
\hline
\end{tabular}

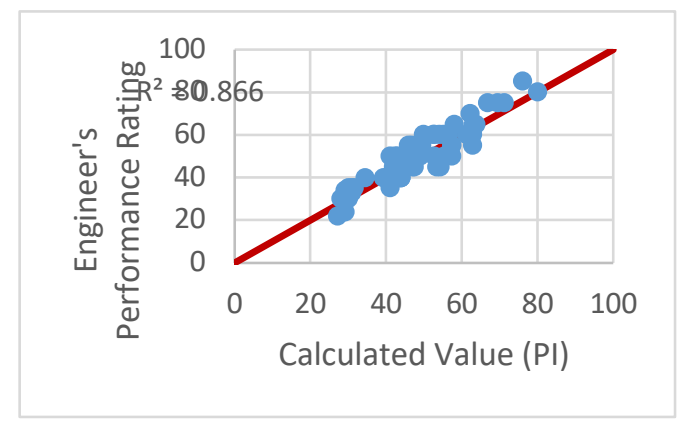

Fig. 4. Scatter plot of Engineer's performance rating and calculated performance index using coefficient from the optimization analysis

The use of new coefficients made slight improvements to the model, with increased correlation coefficient of 0.931 and a RMSE value of 5.28. This suggests that the model can predict the performance index of the road section at an acceptable accuracy level for consistency.

The final performance index function is given as follows.

$$
\mathrm{PI}=28.7 w_{R}+24.7 w_{S}+33.4 w_{H}+4.7 w_{N}+3.3 w_{F}+5.2 V(3)
$$

where, $w_{R}, w_{S}, w_{H}, w_{N}, w_{F}, V$ are the adjustment factor for rod width, shoulder condition, highway structures, narrow bends, road furniture and average travel speed respectively.

\section{B. Model validation}

The calibrated model (3) was next tested for its validity using a similar set of data. Fig. 5 depicts the scatterplot of the data. It was observed that the developed model sufficiently predicted the Engineers Performance Rating given that the correlation coefficient was 0.900 and RMSE value was 4.92.

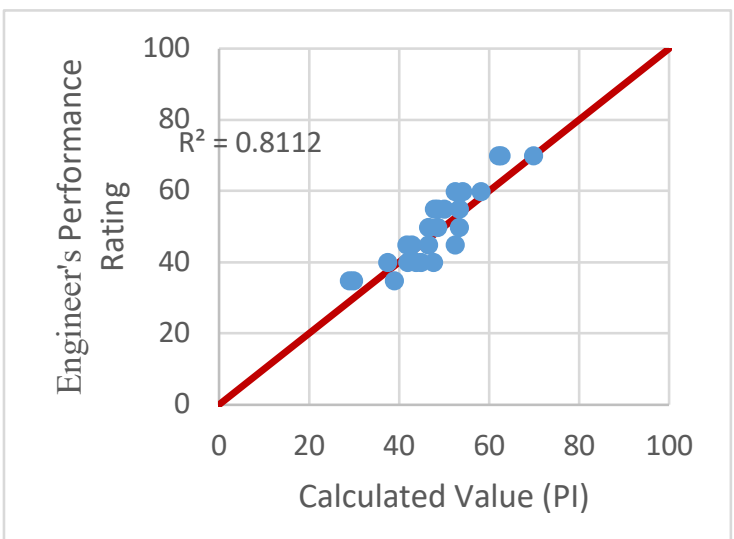

Fig. 5. Scatter plot of Engineer's performance rating and calculated performance index of data set used for validation

\section{CONCLUSION}

The study proposes a simple methodology to evaluate the performance index of roads. It addresses a unique problem encountered by road agencies when selecting roads for upgrading. Conventional level of service analysis methods which focus on traffic operations and pavement management related methods which focus on road condition or life cycle costs does not sufficiently address the requirements relevant to this issue, where focus should be on the need to improve roadway conditions. This is especially relevant to provincial level roads with low to moderate traffic flows. This can be used in the prioritization of the roads in the network for upgrading projects.

This incorporates the roadway and operational parameters that has the most significant impact on the overall performance of the road. The required data can be easily collected using the limited resources available in the provincial level road agencies. The addition of other relevant parameters can be done using the same methodology. The model as shown in the case study can be calibrated to represent the considerations of the respective agency.

The results of the model can be incorporated into prioritization criterion to make decisions with respect to network upgrading planning. This will eliminate the need to use subjective judgment in the planning process and eliminate undue influences in making prioritization decisions and evaluate the overall network performance. Therefore, the proposed method, offers an objective method which requires minimal resources to implement in the planning process to be used as a tool to prioritize road upgrading projects.

\section{ACKNOWLEDGEMENT}

This research was supported by a Senate Research Committee (SRC) Grant of University of Moratuwa. (SRC/LT/2017/04).

\section{REFERENCES}

[1] Central Bank of Sri Lanka. "Economic and Social Statistics of Sri Lanka 2014," Colombo: Statistics Department, 2014. 
[2] Central Bank of Sri Lanka. "Annual Report 2016," Colombo: s.n, 2016.

[3] Transport Research Board, 2010. "Highway Capacity Manual. Transportation Research Board," National Research Council, Washington, DC, 2010.

[4] Directorate General of Highways, "Indonesian Highway Capacity Manual," Jakarta: s.n, 1993.

[5] Indian Roads Congress. "Guidelines for Capacity of Roads in Rural Areas," New Delhi: Indian Roads Congress, 1990.

[6] I.H. Hashim and T.A. Abdel-Wahed. "Evaluation of performance measures for rural two-lane roads in Egypt," AEJ, 50, 2013, pp. 245-255.

[7] Oregon Department of Transportation. "Modelling Performance Indicators on Two Lane Rural Highways," Oregon DOT, Oregon, 2010.

[8] C. Van As. "The Development of an Analysis Method for the Determination of Level of Service of Two-lane Undivided Highways in South Africa," South African National Roads Agency Limited, 2003. 